\title{
FREQUENCY OF EXTERNAL ROOT RESORPTION IN MANDIBULAR SECOND MOLARS ASSOCIATED WITH MANDIBULAR IMPACTED THIRD MOLARS IN A SAMPLE OF EGYPTIAN POPULATION USING CBCT: A CROSS-SECTIONAL STUDY
}

\author{
Rawan A. Elkassas*, Salma B. Eiid** and Dina M. El Beshlawy***
}

\begin{abstract}
Aim: To investigate the prevalence and risk factors of external root resorption (ERR) in mandibularsecond molars adjacent to impacted third molars in a sample of Egyptian population.

Methodology: CBCTscans involving 255 mandibular impacted third molars were included. Demographic factors (age and gender) and Radiographic factors(impaction angulation and impaction depth) were assessed. The presence of ERR and distal caries in mandibular second molarand their association with the demographic and radiographic data was analyzed. Statistical analysis was performed using IBM SPSS Statistics Version 2.0 for Windows.

Results: The prevalence of ERR was $18.4 \%$ in mandibular second molars with higher occurrences in horizontal and mesioangular third molars classified as class B and $\mathrm{C}(\mathrm{P}=0.001$, $\mathrm{P}=0.017)$. Besides, class $\mathrm{C}$ impaction increased the risk of ERR severity in second molars $(\mathrm{P}<$ $0.05)$. The prevalence of caries was $14.5 \%$, with increased caries severity with class A impaction $(\mathrm{P}<0.001)$.
\end{abstract}

Conclusions: ERR and distal caries occurring in mandibular second molars adjacent to impacted third molarsshould not be neglected. ERR should be suspected with horizontal and mesioangular third molars classified as class B and C impaction depth.

KEYWORDS: External root resorption, Impacted third molar, Second molar, Conebeamcomputed tomography

* Former internal resident, Oral and Maxillofacial Radiology Department, Faculty of Dentistry, Cairo University, MSc Degree Candidate, Oral and Maxillofacial Radiology Department, Faculty of Dentistry, Cairo University.

** Lecturer, Oral and Maxillofacial Rdiology Department, Faculty of Dentistry, Cairo University.

*** Professor, Oral and Maxillofacial Radiology Department, Faculty of Dentistry, Cairo University. 


\section{INTRODUCTION}

Impacted third molars can predispose adjacent second molars to unfavorable effects such as external root resorption (ERR), distal caries and periodontal problems. ${ }^{(2,13,22)}$ This unfortunately may lead to development of pulpitis or apical periodontitis in second molars ${ }^{(9)}$ with pain and discomfort to the patient, and endodontic treatment or possibly extraction of the tooth with its consequent health and functional problems. ${ }^{(6,16)}$

Accordingly, it is necessary to study the frequency of the pathological findings in second molars associated with impacted third molars, and to highlight both patient and tooth specific risk factors associated with those pathological effects. Tooth specific factors include the position and the angulation of the impacted third molar, and patient specific factors include age and gender, all of which could lead to the development of pathologic conditions in adjacent second molars. ${ }^{(1,25)}$ Knowledge of these risk factors will help in early detection and prevention of ERR in second molars. ${ }^{(4)}$ Moreover, the association of these risk factors to the development of pathological effects, may add valuable knowledge in the indications for removal of the impacted third molar, ${ }^{(13)}$ as prophylactic removal of impacted third molars still remains controversial in the literature up till now. ${ }^{(5)}$

Cone beam computed tomography (CBCT) provides 3D multiplanar imaging with no superimposition (compared to conventional imaging techniques), low radiation dose and high spatial resolution. ${ }^{(23)}$ Furthermore, CBCT has been used as a diagnostic tool to detect different pathological conditions in second molars associated with impacted third molar. ${ }^{(9,18)}$ Therefore, CBCT can provide detailed information of the proximity and relationship of second molars and third molars in the three dimensions, rendering analysis of risk factors of ERR of second molars more accurate. ${ }^{(5)}$

This is the first study to be conducted among Egyptian population using CBCT and it sought to detect the frequency of ERR in second molars adjacent to impacted third molars, and identify the association of this pathological findings with tooth specific and patient specific risk factors.

\section{MATERIALS AND METHODS}

In this observational cross-sectional retrospective study, a total sample of 255 mandibular second permanent molars adjacent to partially or totally impacted mandibular third molars, and belonging to 181 Egyptian patients was included according to sample size calculation using Epi info TM statistical software based on the previous paper by Tassoker. (22) A total of 255 hemi-mandibles were needed for $21 \%$ prevalence of ERR, a margin of error of $5 \%$, and a $95 \%$ confidence interval.

\section{Eligibility criteria and selection method}

Scans of patients having more than 18 years old and most permanent teeth erupted were included, whereas, scans having completely erupted third molars, impacted third molars with pathologic lesions, developing third molars with root development less than two-thirds, missing second or third molars, image artifacts were excluded from this study.

\section{Demographic data}

The gender and the age of each case were recorded. Age was categorized into 3 age ranges; (1824), (25-34) and (35-50) according to Tassoker. ${ }^{(22)}$

\section{Image Assessment}

All image analysis procedures were performed by the main investigator who evaluated the images twice at separate sessions with a time lag of 2 weeks. The 3D module in OnDemand software was used during the image analysis. The observer was free to use the image enhancement tools as brightness, contrast, and magnification tools. Teeth specific factors (impaction angulation and level) and frequency of pathological problems associated with impactions were assessed. 


\subsection{Teeth specific factors (angulation and level)}

The angulation of the impacted $3^{\text {rd }}$ molar was defined by using the "four point" angle measurement tool in the software where the angle between the occlusal surfaces of both the $2^{\text {nd }}$ and $3^{\text {rd }}$ molars was measuredand Winter's angulation ${ }^{(24)}$ was defined according to Shiller ${ }^{(20)}$ and $\mathbf{~ L i ~ e t ~ a l ~}{ }^{(10)}$ as follows: 1. Distoangular Angulation: <- $15^{\circ}, 2$. Vertical Angulation: $-15^{\circ}$ to $15^{\circ}, 3$. Mesioangular Angulation: $16^{\circ}-75^{\circ}$ and 4 . Horizontal Angulation: $>75^{\circ}$.

Impacted third molars level was defined according to Pell and Gregory ${ }^{(19)}$ where inposition A the highest portion of the tooth is leveled with/above the occlusal plane of the second molar, in position $\mathrm{B}$ the highest portion of the tooth is below the occlusal plane, but above the cervical line of the second molarand in position $\mathrm{C}$ The highest portion of the tooth is below the cervical line of the second molar.

\subsection{Detection of ERR in Roots of 2nd Molars}

ERR was considered present when there was a clear loss of substance in the root of mandibular second molar teeth due to its direct contact with the adjacent impacted third molar. ${ }^{(2)}$ ERR was graded according to severity into: ERR involving less than half the dentine thickness (slight), ERR involving at least half the dentine (moderate) and ERR involving the pulp cavity (severe) according to Ericson et al. ${ }^{(7)}$ (Figure 1)

\section{Statistical analysis}

Statistical analysis was performed using IBM SPSS Statistics Version 2.0 for Windows. Data was presented as mean, standard deviation (SD), absolute (n) and relative (\%) frequencies. KolmogorovSmirnov and Shapiro-Wilk tests were used to assess data normality of continuous data. The significance level was set at $\mathrm{P} \leq 0.05$.

Ninety-five percent confidence interval was calculated for prevalence of external root resorption of mandibular second molars and its severity as well as impacted third molar angulation and depth. Pearson's Chi-square test was used to identify the association of external root resorption, distal caries in mandibular second molars and their severity with demographic and radiographic characteristics.

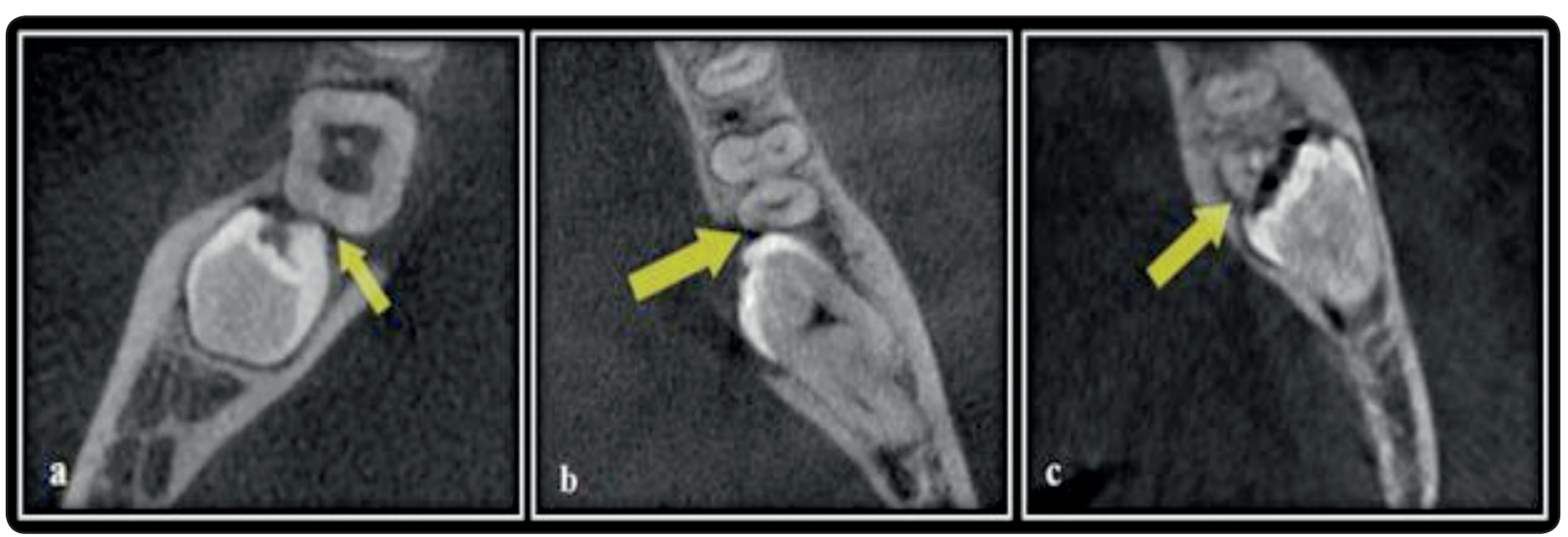

Fig. (1): ERR severity grading. Axial cuts showing a. Slight, b. Moderate and c. Severe ERR. 


\section{RESULTS}

Among the 255 mandibular second molars, only 47 cases showed ERR (18.4\%, 95\% CI: 0.13-0.23). ERR severity was slight in 41 cases $(87.2 \%, 95 \%$ CI: $0.74-0.95)$, moderate in 5 cases $(10.6 \%, 95 \%$ CI: $0.03-0.23)$ and severe in 1 case $(2.1 \%, 95 \%$ CI: 0.0005-0.11).

Regarding ERR prevalence, there was no significant association with age group and gender $(\mathrm{P}=0.772$ and $\mathrm{P}=0.370$, respectively). On the other hand, there was a significant association with impaction angulation and depth $(\mathrm{P}=0.001$ and $\mathrm{P}=0.017$, respectively). ERR was significantly detected only in horizontal and mesioangular impacted third molars and pro- portionally higher in classes B and C.

Regarding ERR severity, there was no significant association with impaction angulation $(\mathrm{P}=0.148)$, while; there was a significant association with impaction depth $(\mathrm{P}=0.004)$. Slight ERR was proportionally higher with impacted third molars classified as A and B, and severe ERR was proportionally higher with impacted third molars classified as $\mathrm{C}$ (Table 1).

Kappa test showed perfect intra-observer agreement regarding angulations (kappa $=1.000$, $\mathrm{P}<0.001$ ), depths (kappa $=1.000, \mathrm{P}<0.001)$, prevalence of root resorption (kappa $=1.000, \mathrm{P}<0.001)$ and severity of root resorption (kappa=1.000, $\mathrm{P}<0.001)$.

TABLE (1): Association of external root resorption severity with radiographic characteristics.

\begin{tabular}{|c|c|c|c|c|c|}
\hline & & Slight & Moderate & Severe & P-value \\
\hline \multirow{4}{*}{$\begin{array}{l}\text { Impaction } \\
\text { angulation }\end{array}$} & Vertical & $0(0 \%)$ & $0(0 \%)$ & $0(0 \%)$ & \multirow{4}{*}{$0.148 \mathrm{NS}$} \\
\hline & Horizontal & $17(77.3 \%)$ & $4(18.2 \%)$ & $1(4.5 \%)$ & \\
\hline & Mesioangular & $24(96.0 \%)$ & $1(4.0 \%)$ & $0(0 \%)$ & \\
\hline & Distoangular & $0(0 \%)$ & $0(0 \%)$ & $0(0 \%)$ & \\
\hline \multirow{3}{*}{ Impaction depth } & A & $8(88.9 \%)^{\mathrm{a}}$ & $1(11.1 \%)^{\mathrm{a}}$ & $0(0 \%)^{\mathrm{b}}$ & \multirow{3}{*}{$0.004 *$} \\
\hline & B & $31(88.6 \%)^{\mathrm{a}}$ & $4(11.4 \%)^{\mathrm{a}}$ & $0(0 \%)^{\mathrm{b}}$ & \\
\hline & C & $2(66.7 \%)^{\mathrm{b}}$ & $0(0 \%)^{\mathrm{a}}$ & $1(33.3 \%)^{\mathrm{a}}$ & \\
\hline
\end{tabular}

\section{DISCUSSION}

This study aimed to identify the prevalence and risk factors of ERR of second molars adjacent to partially or completely impacted third molars, in order to enrich the deficient Egyptian database with outcomes that could benefit surgeons and dental practitioners, and adding evidence to supplement the ongoing debate as whether to prophylactically extract impacted third molars or not. Since, evidence-based data from well conducted clinical trials and systematic reviews are not yet sufficient to justify the routine prophylactic extraction of impacted third molars. ${ }^{(8)}$

It's worthy to note that Oenning et al. ${ }^{(17)}$ declared that CBCT provides 4.3 times greater detection of ERR than panoramic radiographs. Images with 
a voxel size of 0.2 were only included to provide the highest resolution needed for detection of fine details such as incipient ERR and distal caries.

In the present research, the prevalence of ERR associated with impacted third molars was $18.4 \%$ in mandibular second molars. Our prevalence was relatively lower in relation to previous findings which ranged from 20.2 to $54.9 \%$. ${ }^{(10,12,13,17,18,21-23)}$ This could be due to differences in the inclusion criteria and selection bias problem, where some studies included only mesioangular and horizontal impactions. ${ }^{(18,23)}$

We found no significant association between ERR prevalence and age. This was in agreement with Tassoker ${ }^{(22)}$ and Smailienè et al., (21) but inconsistent with the findings of Wang et al. (23) who reported that being over the age of 35 was a risk factor for ERR. The same relation was found in gender, which was in line with Tassoker. ${ }^{(22)}$ In contrast, some studies have suggested that men are more prone to developing ERR than women, which researchers attributed to the difference in sex hormones. ${ }^{(15,26)}$ Conversely, both the angulation and depth of the impacted third molar were found to be predictive parameters of ERR in the current study. ERR was only associated with horizontal and mesioangular third molars with statistically significant difference. Our findings agreed with studies claiming that mesioangular and horizontal impacted mandibular third molars are risk factors of ERR development in adjacent mandibular second molars. $^{(3,12-14,17,18,22)}$ It was suggested that this could be due to a relatively large contact area between the third and the second molars in case of these angulations.

Additionally, our data revealed that class B and $\mathrm{C}$ impactions were associated with the highest prevalence of ERR in mandibular second molars, which suggests that the cervical area of the root surface and root apical region might be susceptible regions for ERR occurrence. This was in line with previous studies which reported that the apical region was the most susceptible region for ERR (as in class $\mathrm{C}$ impactions) ${ }^{(10,14)}$ Oenning et al., ${ }^{(18)}$ on the one hand, was in accord that class B impaction was related to a higher ERR prevalence in mandibular second molars compared with class $\mathrm{C}$, but on the other hand, they found higher ERR prevalence in class $\mathrm{A}$ as well. Wang et al. ${ }^{(23)}$ found that class A and $\mathrm{C}$ impactions had a higher risk to cause ERR in mandibular second molar when compared with Class B. This inconsistency among the findings might be due to differences in sample size populations among the studies, where sample sizes were only targeting the prevalence of ERR.

In our study, ERR severity was not significantly associated with the impaction angulation, while it was significantly associated with the depth. Neither class A nor B showed severe root resorption in second molars, while ERR severity increased with class $\mathrm{C}$ impactions. This finding agreed with $\mathbf{L i}$ et al. ${ }^{(10)}$ who also found that ERR occurring at the apical third of the root was the most severe. Maybe this is because apical cementum is considerably softer than cervical cementum. ${ }^{(11)}$

We can conclude from the present research that ERR occurring in mandibular second molars adjacent to impacted third molars should not be neglected. ERR should be suspected with horizontal and mesioangular third molars classified as class B and $\mathrm{C}$ impaction depth. Therefore, regular follow up and active surveillance of mandibular second molars adjacent to third molars could be considered by Egyptian dental practitioners, especially with mesially and horizontally impacted teeth showing class B and C depth, to avoid initiation of root resorption of the adjacent second molars. Finally, it's recommended that a larger sample with consistent inclusion/exclusion criteria from multiple worldwide geographical distributions and socioeconomic levels should be carried out to further understanding of mandibular third impaction and its effects on the adjacent second molar. 


\section{REFERENCES}

1. Akarslan, Z. Z., \& Kocabay, C. (2009). Assessment of the associated symptoms, pathologies, positions and angulations of bilateral occurring mandibular third molars: Is there any similarity? Oral Surg Oral Med Oral Pathol Oral Radiol, 108(3): e26-e32.

2. Al-Khateeb, T. H., \&Bataineh, A. B. (2006). Pathology Associated With Impacted Mandibular Third Molars in a Group of Jordanians. J Oral Maxillofac Surg., 64(11): 1598-1602.

3. Camargo, I. B., Sobrinho, J. B., Andrade, E. S. de S., \& Van Sickels, J. E. (2016). Correlational study of impacted and non-functional lower third molar position with occurrence of pathologies.ProgOrthod., 17(1).

4. Chang, S. W., Shin, S. Y., Kum, K. Y., \& Hong, J. (2009). Correlation study between distal caries in the mandibular second molar and the eruption status of the mandibular third molar in the Korean population. Oral Surg Oral Med Oral Pathol Oral RadiolEndod., 108(6): 838-843.

5. Chen, Y., Zheng, J., Li, D., Huang, Z., Huang, Z., Wang, X., Zhang, X., Hu, X. (2020). Three-dimensional position of mandibular third molars and its association with distal caries in mandibular second molars: a cone beam computed tomographic study. Clin Oral Investig., 24(9): 3265-3273

6. Enabulele, J. E., \&Obuekwe, O. N. (2017). Prevalence of caries and cervical resorption on adjacent second molar associated with impacted third molar. J Oral MaxillofacSurg Med Pathol., 29(4): 289-394.

7. Ericson, S., Bjerklin, K., \&Falahat, B. (2002). Does the Canine Dental Follicle Cause Resorption of Permanent Incisor Roots ? A Computed Tomographic Study of Erupting Maxillary Canines. Angle Orthod., 72(2): 14-18.

8. Garrocho-Rangel DDS, PhD, A., Pozos-Guillén DDS, PhD, A., Noyola-Frías DDS, M. Á., Martínez-Rider DDS, R., \& González-Rivas DDS, B. (2017). Prophylactic Extraction of Third Molars: Evidence-Based Dentistry. Odovtos-IntJ Dent Sc., 19(3): 10

9. Kang, F., Huang, C., Sah, M. K., \& Jiang, B. (2016). Effect of Eruption Status of the Mandibular Third Molar on Distal Caries in the Adjacent Second Molar. J Oral Maxillofac Surg., 74(4): 684-92.

10. Li, D., Tao, Y., Cui, M., Zhang, W., Zhang, X., \& Hu, X. (2019). External root resorption in maxillary and mandibu- lar second molars associated with impacted third molars: a cone-beam computed tomographic study. Clin Oral Investig., 23(12): 4195-4203.

11. Malek, S., Darendeliler, M. A., \& Swain, M. V. (2001). Physical properties of root cementum: Part I. A new method for 3-dimensional evaluation.Am J Orthod Dentofacial Orthop., 120(2): 198-208.

12. Matzen, Louise H., Petersen, L. B., \& Wenzel, A. (2016). Radiographic methods used before removal of mandibular third molars among randomly selected general dental clinics. DentomaxillofacRadiol., 45(4): 20150226.

13. Matzen, Louise Hauge, Schropp, L., Spin-Neto, R., \& Wenzel, A. (2017). Use of cone beam computed tomography to assess significant imaging findings related to mandibular third molar impaction. Oral Surg Oral Med Oral Pathol Oral Radiol., 124(5): 506-516.

14. Nemcovsky, C. E. (1996). Effect of non-erupted 3rd molars on distal roots and supporting structures of approximal teeth A radiographic survey of 202 cases. J ClinPeriodontol., 23(9): 810-815.

15. Nitzan, D., Keren, T., \& Marmary, Y. (1981). Does an impacted tooth cause root resorption of the adjacent one? Oral Surg Oral Med Oral Pathol., 51(3): 221-224.

16. Nowjack-Raymer, R. E., \& Sheiham, A. (2007). Numbers of Natural Teeth, Diet, and Nutritional Status. J Dent Res., 86(12): 1171-1175.

17. Oenning, A. C. C., Neves, F. S., Alencar, P. N. B., Prado, R. F., Groppo, F. C., \&Haiter-Neto, F. (2014). External root resorption of the second molar associated with third molar impaction: Comparison of panoramic radiography and cone beam computed tomography. J Oral Maxillofac Surg., 72(8): 1444-1455.

18. Oenning, A. C. C., Sousa Melo, S. L., Groppo, F. C., \& Haiter-Neto, F. (2015). Mesial inclination of impacted third molars and its propensity to stimulate external root resorption in second molars - A cone-beam computed tomographic evaluation. J Oral Maxillofac Surg., 73(3): 37986.

19. Pell GJ, Gregory BT. (1933). Impacted mandibular third molars: Classification and modified techniques for removal. Dent Dig, 39:330-8.

20. Shiller, W. R. (1979). Positional changes in mesio-angular impacted mandibular third molars during a year. J Am Dent Assoc., 99(3): 460-464. 
21. Smailienè, D., Trakinienè, G., Beinorienè, A., \& Tutlienè, U. (2019). Relationship between the position of impacted third molars and external root resorption of adjacent second molars: A retrospective CBCT study. Medicina (Kaunas)., 55(6): 305.

22. Tassoker, M. (2018). What Are the Risk Factors for External Root Resorption of Second Molars Associated With Impacted Third Molars? A Cone-Beam Computed Tomography Study. J OralMaxillofac Surg. 77(1): 11-17.

23. Wang, D., He, X., Wang, Y., Li, Z., Zhu, Y., Sun, C., Ye, J., Jiang, H., Cheng, J. (2017). External root resorption of the second molar associated with mesially and horizontally impacted mandibular third molar: evidence from cone beam computed tomography. Clin Oral Investig., 21(4), 1335-1342.

24. Winter G. B. (1926): Impacted mandibular third molars, p: 241-279, American Medical Book Company, St Louis: Mosby.

25. Yamalik, K., \&Bozkaya, S. (2008). The predictivity of mandibular third molar position as a risk indicator for peri coronitis. Clin Oral Investig., 12(1):9-14.

26. Yamaoka, M., Furusawa, K., Ikeda, M., \& Hasegawa, T. (1999). Root resorption of mandibular second molar teeth associated with the presence of the third molars. Aust Dent J, 44(2): 112-116. 